\title{
A neurosarcoidosis case with pituitary stalk involvement manifesting as hypogonadism and hyperprolactinemia
}

\author{
Asli Nar, Ozlem Turhan lyidir, Sevde Nur Firat, Neslihan Bascil Tutuncu \\ Department of Endocrinology and Metabolism, Baskent University Faculty of Medicine, Ankara, Turkey
}

\section{Introduction}

\begin{abstract}
Sarcoidosis is a multisystem granulomatous disease of unknown cause. Its characterized by noncaseating granulomas in affected organs. The prevalence of disease is estimated to be $1 / 5000$. The pulmonary involvement is the most frequent manifestation. Neurosarcoidosis may involve central and peripheral nervous system. The prevalence of neurosarcoidosis is about 5-15\%. Neurosarcoidosis carries a poor prognosis with mortality of $10-18 \%$. Hypothalamopituitary (HP) sarcoidosis is even rarer ( $<1 \%$ of cases evaluated for sellar and stalk lesions and $2.5 \%$ in patients with neurosarcoidosis). Only a few studies described HP involvement which suggested that central hypogonadism, central hypothyroidism, hyperprolactinemia and diabetes insipidus were the most common hormonal problems. There is no consensus about the treatment but the control of the disease and the replacement of hormonal deficiencies are mandatory. High dose glucocorticoids and immunomodulators in the second place are considered as the mainstays of the treatment.

We present here a neurosarcoidosis case with pituitary stalk involvement manifesting as hypogonadism and hyperprolactinemia
\end{abstract}

\section{Case Report}

A 33-year-old man presented to urology department with erectile dysfunction which started six months ago. Hormonal evaluation revealed gonadotropin deficiency and hyperprolactinemia (Total testosterone: $30,5 \mathrm{ng} / \mathrm{dl}$ (N: 241-827), LH: $2 \mathrm{mIU} / \mathrm{ml}, \mathrm{FSH}: 1,9 \mathrm{mIU} / \mathrm{ml}, \mathrm{PRL}: 32,2 \mathrm{ng} / \mathrm{ml}$ (N: 2,1-17,7). His sellar MRI showed uniformly thickened pituitary stalk and gadolinium-enhancement of leptomeninges, posterior limb of internal capsule, base of third ventricle, suprasellar- perioptic regions, cerebellar hemispheres and pineal gland (Fig. 1). There was no problem in his vision. Ophthalmologic evaluation revealed full visual fields. He denied polydipsia and polyuria.

His medical history uncovered that he was diagnosed as pulmonary sarcoidosis four years ago for which he didn't receive any specific therapy and was lost of follow-up. He was diagnosed with deep venous thrombosis of lower extremity 4 months ago. Patient was put on anticoagulation therapy.

Bilateral hilar and mediastinal adenopathy was detected on thorax CT. The endobronchial ultrasound-guided transbronchial needle aspiration of hilar lymph node showed noncaseating granulomas consistent with sarcoidosis. These findings suggested a diagnosis of neurosarcoidosis with pituitary stalk involvement. This patient was treated with an initial dose of po methylprednisolon $(1 \mathrm{mg} / \mathrm{kg} / \mathrm{day})$ which was then tapered weekly and azathioprine (150 $\mathrm{mg}$ /day) was added two months later because of partial pulmonary response (chronic cough). Testosterone replacement was also initiated. MRI abnormalities regressed partially after 6 months of treatment accompanied by prolactin normalisation without any change in gonadotropin deficiency (Fig. 2, Table 1). In the second month of glucocorticoid and testosterone treatment, his wife became pregnant.

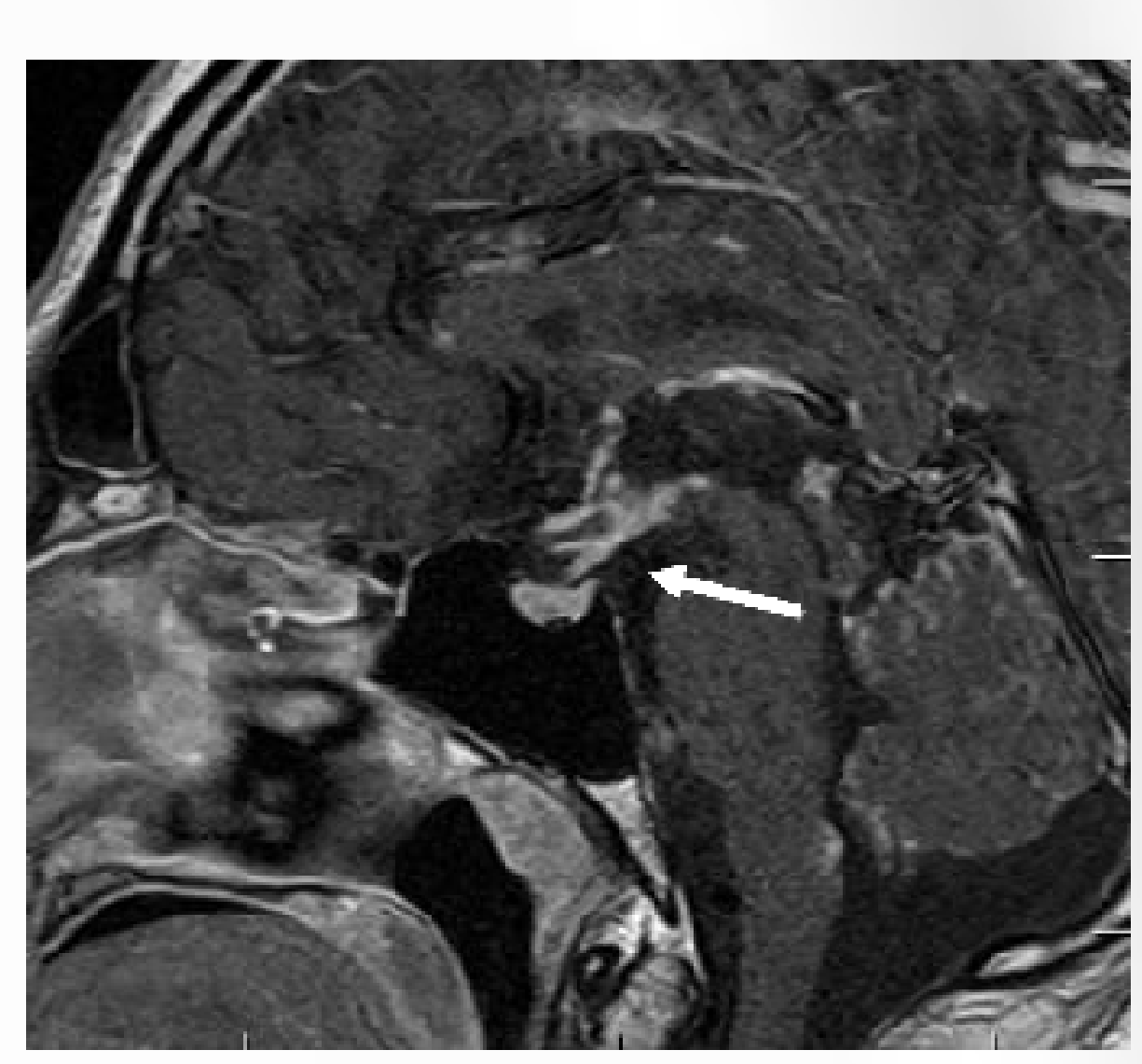

Fig. 1 T1 post contrast sagital MRI image demonstrates thickened pituitary stalk (arrow)

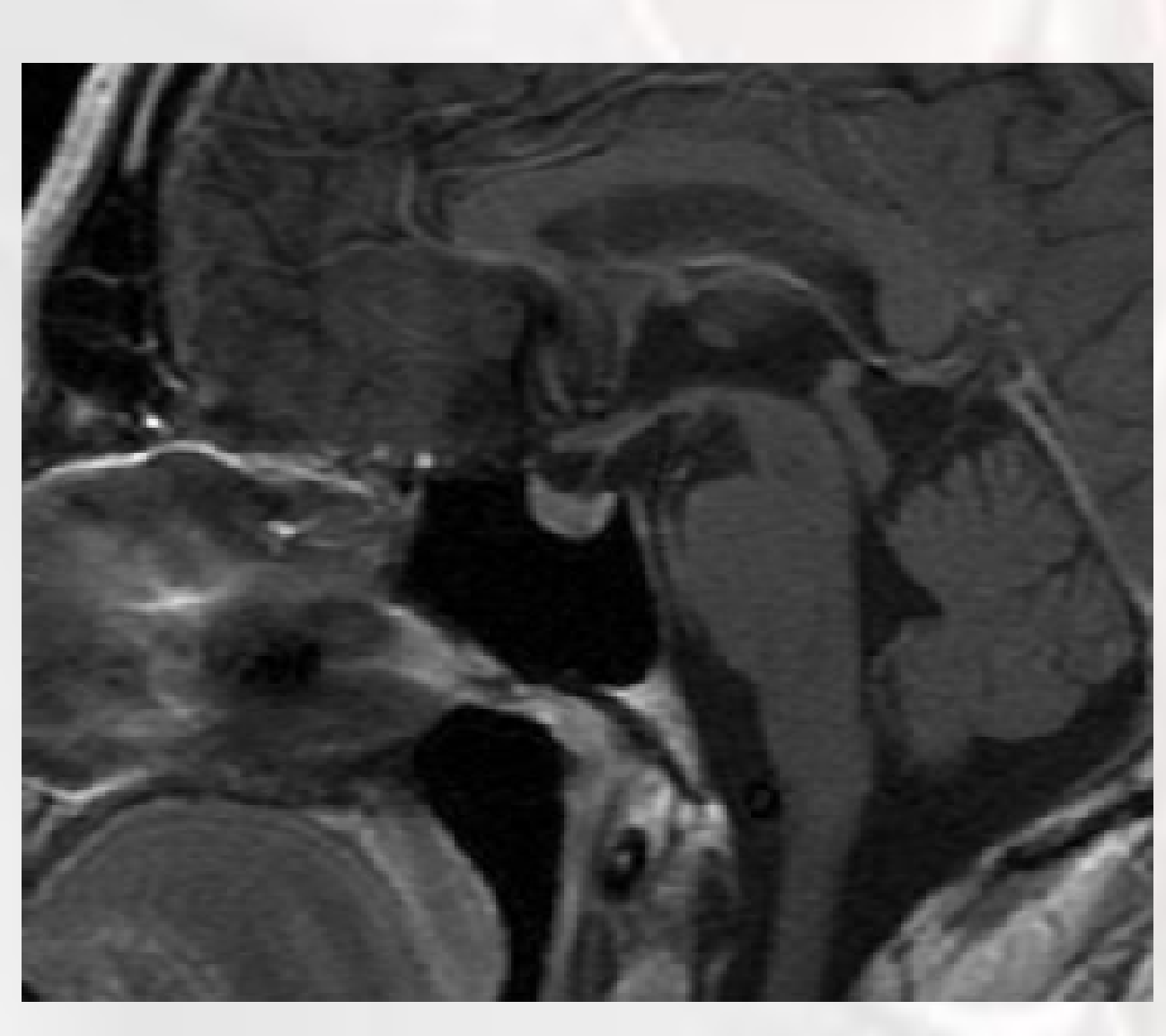

Fig. 2 T1 weighted sagital MRI after 6 months of steroid treatment. The pituitary stalk was decreased in size.

Table 1 Laboratory tests during presentation and after medical treatment

\begin{tabular}{lcc}
\hline Test & Presentation & $\begin{array}{c}\text { During medical } \\
\text { treatment- } \\
\text { Sixth month }\end{array}$ \\
\hline LH $(1,14-8,75 \mathrm{mlU} / \mathrm{ml})$ & 2,04 & 0,58 \\
\hline FSH $(0,95-11,95 \mathrm{mlU} / \mathrm{ml})$ & 1,94 & 0,66 \\
\hline Total testosteron $(241-827 \mathrm{ng} / \mathrm{dl})$ & 30,5 & 401 \\
\hline Prolactin : $(2,1-17,7 \mathrm{ng} / \mathrm{ml})$ & 32,2 & 16,8 \\
\hline TSH $(0,35-4,94 \mu \mathrm{lU} / \mathrm{ml})$ & 0,86 & 1,11 \\
\hline Free T4 $(0,7-1,48 \mathrm{ng} / \mathrm{dl})$ & 0,91 & 1,1 \\
\hline IGF $-1(142-405 \mathrm{ng} / \mathrm{ml})$ & 257 & 346 \\
\hline Cortisol $(3,7-19,4 \mu \mathrm{g} / \mathrm{dl})$ & 18,3 & 5,67 \\
\hline
\end{tabular}

Conclusion

The present patient had previously diagnosed and untreated sarcoidosis. During the work-up of hypogonadism, HP neurosarcoidosis was diagnosed. The pituitary involvement is usually associated with severity of sarcoidosis and hypogonadism is the most frequent manifestation. It is followed by central hypothyroidism, hyperprolactinemia, diabetes insipidus, low IGF-1 and adrenocortical insufficiency. The patients with HP involvement were younger at diagnosis of sarcoidosis than the systemic sarcoidosis patients in the literature. Our patient was 29 when sarcoidosis was diagnosed and 33 years old when he was diagnosed with HP sarcoidosis. Sarcoidosis is also significantly associated with thrombosis risk as our case.

There is no consensus about treatment of HP neurosarcoidosis. Case series show systemic high dose glucocorticoids as the mainstay of treatment. The follow-up and tapering is individualized. If sarcoidosis worsens or side effects of glucocorticoids appear, various immunomodulators are tried. Immunomodulators used are methotrexate, azathioprine, cyclosporine, infliximab and mycophenolate mofetil. Glucocorticoid and immunosuppressive therapy may improve MRI findings but effect on hormonal dysfunction seems to be limited as in our case. Prolactin was normalised after the treatment of our case. The literature data suggests that granulomatous infiltration may induce early definitive damage of the pituitary cells. A review indicated that only $10 \%$ of patients had biochemical improvement in response to high-dose glucocorticoid treatment. It may be explained by cellular destruction as a result of glanuloma formation or fibrosis.

Patients need long term management by a multidisciplinary approach. Physicians should be aware of hypothalamo-pituitary involvement of sarcoidosis since earyl treatment may rescue pituitary functions. Endocrine symptoms should be checked during consultations.

\section{References}

1- Langrand C, Bihan H, Raverot G et al Hypothalamopituitary sarcoidosis: a multicenter study of 24 patients. QJM Month J Assoc Phys 2012;105:981-995

2- Bihan $\mathrm{H}$, Christozova V, Dumas JL et al. Sarcoidosis: clinical, hormonal, and magnetic resonance imaging (MRI) manifestations of hypothalamic-pituitary disease in 9 patients and review of the literature. Medicine 2007;86:259-268

3- Anthony J, Esper GJ, loachimescu A. Hypothalamic-pituitary sarcoidosis with vision loss and hypopituitarism: case series and literature review. Pituitary. 2016 Feb;19(1):19-29

4- Tanaka K1, Yamamoto M, Okazaki K, Yamaguchi T, Sugimoto T. Partial Improvement of anterior Pituitary Deficiency Following Steroid Treatment in a Patient with Neurosarcoidosis Accompanied by Central Diabetes Insipidus. Intern Med. 2012;51(16):2175-9 